INNOVATIVE CLEAN COAL TECHNOLOGY (ICCT)

\title{
DEMONSTRATION OF INNOVATIVE APPLICATIONS OF TECHNOLOGY FOR COST REDUCTIONS TO THE CT-121 FGD PROCESS
}

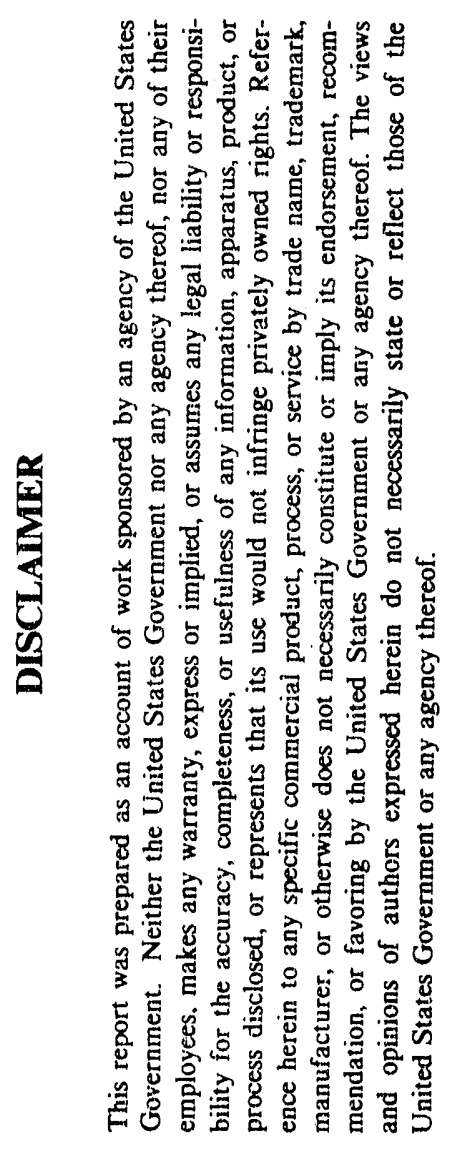

\author{
DOE Contract \\ DE-FC22-90PC89650 \\ SCS Contract \\ C-90-000284 \\ Quarterly Report No. 6 \\ For the Period \\ July - September, 1991
}

November 15, 1991

Prepared by:

Southern Company Services, Inc.

800 Shades Creek Parkway

Birmingham, Alabama 35209

Patents Cleared by Chicago on December 30, 1991

\section{MASTER}


This report was prepared by Southern Company Services, Inc. pursuant to a cooperative agreement partially funded by the U.S. Department of Energy and neither Southern Company Services, Inc. nor any of its subcontractors nor the U.S. Department of Energy, nor any person acting on behalf of either:

(a) Makes any warranty or representation, express or implied with respect to the accuracy, completeness, or usefulness of the information contained in this report, or that the use of any information, apparatus, method, or process disclosed in this report may not infringe privately-owned rights; or

(b) Assumes any liabilities with respect to the use of, or for damages resulting from the use of, any information, apparatus, method or process disclosed in this report.

Reference herein to any specific commercial product, process, or service by trade name, trademark, manufacturer, or otherwise, does not necessarily constitute or imply its endorsement, recommendation, or favoring by the U.S. Department of Energy. The views and opinion of authors expressed herein do not necessarily state or reflect those of the U.S. Department of Energy. 


\section{SUMMARY}

The objective of this project is to demonstrate on a commercial scale several innovative applications of cost-reducing technology to the Chiyoda Thoroughbred-121 (CT-121) process. CT-121 is a second generation flue gas desulfurization (FGD) process which is considered by the Electric Power Research Institute (EPRI) and Southern Company Services (SCS) to be one of the most reliable and lowest cost FGD options for high-sulfur coal-fired utility boiler applications. Demonstrations of the following innovative design approaches will further reduce the cost and provide a clear advantage to CT-121 relative to competing technology:

- use of fiberglass reinforced plastic (FRP) to construct the absorber vessel, wet ducts, and chimney (stack),

- elimination of flue gas reheat,

- elimination of the need for a spare absorber, and

- use of a single vessel to obtain simultaneous particulate and $\mathrm{SO}_{2}$ removal.

The demonstration will be performed at Georgia Power Company's Plant Yates Unit No. 1 (100 MW capacity) near Newnan, Georgia. The project will be funded by the U. S. Department of Energy (DOE), SCS (on behalf of the entire Southern electric system), and EPRI. SCS is the participant responsible for managing all aspects of this project.

The project is being conducted in the following three phases:

Phase I - Permitting and Preliminary Engineering;

Phase II - Detailed Design, Construction, and Startup; and

Phase III - Operations, Testing, and Disposition.

In Phase I, permitting activities were initiated by both SCS and Georgia Power to obtain air, water and gypsum disposal permits with all environmental permit applications necessary for the Yates Project submitted. The Environmental Monitoring Plan has also completed and submitted to DOE for review. A second set of groundwater samples were obtained from the gypsum stack site, and environmental reporting activities were initiated. The primary Phase I activity remaining is the approval of the gypsum stack Design \& Operating (D \& O) Plan. Several iterations of comments from the state have been responded to by Georgia Power, however, it is uncertain as to when the state will consider approval and issuance of this last remaining permit. The completion of the system design basis document which will outline important process design decisions made during preliminary engineering is expected before the end of the year also. Detailed engineering activities began to draw to a close and the JBR reached $98 \%$ completion this quarter. 


\section{INTRODUCTION}

The Innovative Clean Coal Technology (ICCT) Program is designed to demonstrate clean coal technologies that are capable of retrofitting or repowering existing facilities to achieve efficiency improvements and/or significant emissions reduction, specifically in sulfur dioxide $\left(\mathrm{SO}_{2}\right)$ and/or nitrogen oxides (NOx) emissions. The technologies selected for demonstration on the Southern electric system are capable of being commercialized in the 1990s and are expected to be more cost effective than current technologies.

This ICCT project is jointly funded by the U.S. Department of Energy, the Electric Power Research Institute (EPRI), and Southern Company Services (SCS) on behalf of the entire Southern electric system. The project's objective is to demonstrate innovative applications of technology for cost reduction for the Chiyoda Thoroughbred121 (CT-121) process. The CT-121 process is a second generation flue gas desulfurization (FGD) process that EPRI and SCS consider to be one of the least cost FGD processes in its current commercial configuration as evidenced in recent EPRI work (GS-7193, Economic Evaluations of FGD Systems, 1991). Further cost reductions will only make this process even more competitive and more attractive to electric utilities.

The CT-121 process is a wet FGD process that removes $\mathrm{SO}_{2}$, can achieve simultaneous particulate control, and can produce a salable by-product gypsum thereby reducing or even eliminating solid waste disposal problems. Figure 1 shows a flow schematic of the process. CT-121 removes $\mathrm{SO}_{2}$ and particulate matter in a unique limestone-based scrubber called the Jet Bubbling Reactor (JBR). In the JBR, flue gas bubbles beneath the slurry, $\mathrm{SO}_{2}$ is absorbed, and particulate matter is removed from the gas. The agitator circulates limestone slurry to ensure that fresh reactant is always available in the bubbling or froth zone so that $\mathrm{SO}_{2}$ removal can proceed at a rapid rate. Air is introduced into the bottom of the JBR to oxidize the absorbed $\mathrm{SO}_{2}$ to sulfate, and limestone is added continuously to neutralize the acid slurry and form gypsum. The JBR is designed to allow ample time for complete oxidation of the $\mathrm{SO}_{2}$, for complete reaction of the limestone, and for growth of large gypsum crystals. The gypsum slurry is continuously withdrawn from the JBR and is to be dewatered in a gypsum stack. The stacking technique involves filling a diked area with gypsum slurry, allowing the gypsum solids to settle, and removing clear liquid from the top of the stack for recycle back to the process.

The CT-121 process is in widespread commercial use in Japan and at one location in the United States. At the University of Illinois, a 45 MW CT-121 process began operations in 1988 on a stoker boiler, which is not a typical utility application. In Japan, commercial CT-121 processes are used to treat the flue gas from boilers which burn oil or low-sulfur coal. Some of the oil-fired units do not include particulate control devices upstream of the CT-121 processes, another atypical application. 
- The purpose of this ICCT project is to demonstrate the process on high-ash and high-sulfur. U.S. coal using several design modifications that will reduce the estimated cost of the present CT-121 process by 23 percent for power plant retrofit applications and up to 50 percent for new power plant installations. This will be accomplished while maintaining 90 percent $\mathrm{SO}_{2}$ removal and high particulate removal efficiency. A reusable gypsum byproduct will also be produced during the project.

The major cost-reducing design changes to be demonstrated are:

- using less expensive materials of construction (FRP),

- eliminating a spare absorber module,

- eliminating flue gas reheat, and

- combining $\mathrm{SO}_{2}$ and particulate removal in a single vessel.

Utility scale units with the CT-121 processes currently include a prescrubber for control of soluble chloride concentration and use JBRs made of stainless steel, which is relatively expensive. Typically, outlet ducts are lined or made of alloys, and the chimney is lined. Failures are common. Likewise, liners have to be replaced after a period of time which adds additional expense and inconvenience. For this demonstration project, the JBR, inlet duct, and chimney will be made of solid fiberglass-reinforced plastic (FRP) which is unaffected by chlorides or other corrosion mechanisms normally experienced in FGD processes. A successful demonstration of FRP in this project will confirm the absence of need for a prescrubber in the CT-121 process and will also demonstrate a JBR construction material which is less expensive than stainless steel.

This project is intended to demonstrate that the CT-121 process using a JBR made of FRP is highly reliable and does not require a spare absorber module to effectively control $\mathrm{SO}_{2}$ emissions. Current Federal New Source Performance Standards (NSPS) require that spare scrubbers be installed on utility FGD systems if bypass options are to be constructed.

Another cost-saving modification to be demonstrated in this project is the elimination of flue gas reheat downstream of the scrubber. The flue gas leaving any scrubber is at its water dewpoint. Without reheat, subsequent cooling in the ductwork and stack causes moisture to condense into small droplets. These water droplets absorb traces of $\mathrm{SO}_{2}$ and form highly acidic droplets that cause severe corrosion in downstream ducts and stacks. In addition, these droplets tend to fall near the base of the stack (or "rain out"), causing damage to surrounding structures and vehicles. To prevent these problems, this project will use operating techniques and equipment designs that will eliminate the need for costly reheating.

The final cost-saving modification is simultaneous removal of $\mathrm{SO}_{2}$ and particulate matter in the JBR. Typically, an electrostatic precipitator or fabric filter is used upstream of the scrubber to remove particulate matter. In the CT-121 process, greater than 90 percent of the $\mathrm{SO}_{2}$ and 99 percent of the particulate matter in the entering flue gas can be removed in the JBR. When used in new power plants, the elimination of the ESP or fabric filter will result in substantial capital and operating cost reductions. Thus, the CT-121 process provides a cost effective alternative to conventional wet FGD systems. 
- This project will be performed at Georgia Power Company's Plant Yates, Unit No. 1, located about 40 miles southwest of Atlanta between Newnan and Carrollton. The CT-121 process to be installed for this demonstration project will treat the whole flue gas stream generated by the $100 \mathrm{MW}$ Unit 1 boiler. The coal to be burned during the project will be a blend of Illinois \#5 and \#6 coals and will contain between 2.5 and 3 percent sulfur coal.

The demonstration project will be conducted over an 81-month period with project activities including environmental monitoring, permitting, design, construction, operation, process evaluation, and gypsum by-product evaluation. The project is organized into three phases: (1) Phase I - Permitting and Preliminary Engineering; (2) Phase II - Detailed Engineering, Construction, and Startup; and (3) Phase III Operation, Testing, and Disposition. Phase I is scheduled for 8 months, Phase II is scheduled for 27 months with a six-month overlap with Phase I, and Phase III is scheduled for 52 months. Operations are planned for 24 months with the remainder of Phase III activities dedicated to gypsum byproduct utilization and gypsum stack groundwater monitoring studies. The cooperative agreement was signed April 2, 1990, and the project completion date is projected to be mid-1996. The total estimated project costs are $\$ 35,843,678$. The co-funders are SCS $(\$ 11,297,032)$, DOE $(\$ 17,546,646)$, and EPRI $(\$ 7,000,000)$. 


\section{Section 3}

\section{PROJECT DESCRIPTION}

Within the three phases of the project, the following tasks will be conducted to effectively demonstrate a reduced-cost CT-121 process:

Phase I -

Permitting and Preliminary Engineering

Task 1 - Development of Environmental Monitoring

$$
\text { Program }
$$

Task 2 - Permitting Activities

Task 3 - Preliminary Engineering

Task 4 - Gypsim Stack Site Characterization and

Task 5 - $\quad$ Process Engineering Support

Task 6 - Georgia Power Engineering Coordination

Task 7 - Project Management and Reporting

Task 8 - Preliminary Gypsum Stacking and Byproduct

Studies

\section{Phase II - Detailed Design, Construction, and Startup}

Task 1 - Detailed Design Engineering

Task 2 - $\quad$ Process Engineering Support

Task 3 - Georgia Power Engineering Coordination

Task 4 - Construction

Task 5 - Test Plan Development

Task 6 - Training of Operations and Maintenance

\section{Personnel}

Task 7 - $\quad$ Startup

Task 8 - Baseline Groundwater Monitoring

Task 9 - Environmental Data Management and

$$
\text { Reporting }
$$

Task 10 - Project Management and Reporting

Task 11 - Phase II Gypsum Stack Design and Byproduct Studies

Phase III - $\quad$ Operations, Testing, and Disposition

Task 1 - Operations and Maintenance

Task 2 - Process Evaluation

Task 3 - Gypsum Stacking and Byproduct Evaluation

Task 4 - Groundwater Monitoring

Task 5 - Environmental Data Management and Reporting

Task 6 - Economic Analysis

Task 7 - Disposition

Task 8 - Project Management and Reporting 
Section 4

\section{PROJECT STATUS}

Progress during the July - September 1991, quarter is summarized below. Activities continued in the environmental and engineering tasks, and construction activities were brought into full swing.

\section{PHASE I - PERMITTING AND PRELIMINARY ENGINEERING \\ Task 1 - Development of Environmental Monitoring Program}

The Environmental Monitoring Plan was completed by Radian, reviewed by SCS, and submitted to DOE during the last quarter in 1990. This plan includes a quality assurance/quality control plan and sampling and analyses procedures manual. DOE review continues.

\section{Task 2 - Permitting Activities}

The permits required for the project are in three categories: (1) those required during construction, (2) air permits required for operation, and (3) water permits for operation of the process and the gypsum stack. Georgia Power and SCS have continued efforts in all three areas. Previously, Georgia Power obtained permission to conduct fiberglass manufacturing operations at Plant Yates. The air permit has been approved by the state and the FAA has waived any requirement for aviation markers on the FRP chimney. Currently, the state is reviewing the Design \& Operating Plan (D \& O Plan) for the gypsum stack submitted last quarter. The State responded with a request for additional information and clarification, and Georgia Power and SCS responded with the requested information. The final approval is expected sometime in early 1992. Also, a permit for the construction and operation of the chimney elevator was found to be required by an unrelated State office. The permit was quickly secured by SCS.

\section{Task 3 - Preliminary Engineering and}

Task 5-Process Engineering Support

Conceptual process engineering continued during this period. Most process decisions had been made during previous meetings and correspondence with Chiyoda. Representative from Chiyoda visited Yates in June, November and December for additional discussions of the SCS concept and examination of the JBR examination.

\section{Task 4 - Gypsum Stack Site Characterization and Groundwater Well Siting Activities}

Activities to support the gypsum stack permitting effort were completed during the January-March, 1991 quarter. Initial ground clearing was started in September but halted in October. Further construction will not proceed until the state has approved tive D\&O plan and issued a permit (see Task 2 above). 
Phase I activities in this area have been completed. Similar coordination activities are being continued in Phase II.

\section{Task 7-Project Management and Reporting} Phase II.

These activities have been completed for Phase I. Similar activities continue in

\section{Task 8 - Preliminary Gypsum Stacking and Byproduct Studies}

The activities in Phase I have been completed. Additional work is continuing in Phase II as originally proposed. There is also the consideration of providing large quantities of gypsum to several wallboard manufacturers. This would require additional equipment for gypsum washing and is an unfunded, optional activity presently under consideration. A proposal for this additional scope is being drafted and will be offered in early 1992.

\section{PHASE II - DETAILED DESIGN, CONSTRUCTION, AND STARTUP}

Task 1 - Detailed Engineering,

Task 2 - Process Engineering Support, and

Task 3 - Georgia Power Engineering Coordination

The engineering schedule continues to be highly integrated with a number of activities close to the critical path. Thus far, the changes required in schedule in engineering and construction have not affected the May 1992 startup date. However, the continued absence of a permit for the gypsum stacking area may well delay start-up until after the peak summer demand period as tie-in during the June-August time period would not be a good option. The following points summarize progress in the tasks listed above:

- Evaluated bids, awarded contracts, received equipment for the digital data acquisition and control system, miscellaneous power transformer, limestone handling equipment, vertical and horizontal centrifugal pumps, agitators, plant air compressor and motor, and oxidation air blowers.

- Vendors for the flue gas dampers and continuous emissions monitors were selected and contracts awarded. The dampers have been delivered and installed. The continuous emissions monitors are onsite but not yet installed.

- Mist eliminator vendors responded to RFP and evaluations made with DynaGen's participation. A vendor has been selected. 
- Completed design and construction of FRP vessels and completed negotiations with Ershigs concerning the remaining FRP equipment. Problems were identified in the installation quality of the bottom of the Limestone Slurry Tank and bottom of the JBR (Ershigs has scheduled repair work in the next quarter). Due to a cost increase from the 1988 budgetary estimate, SCS elected to eliminate the prescrubber from the design and also elected to build the mist eliminator housing of an alloy clad material rather than FRP. These changes do not affect the project objectives and will result in a reduction in estimated project cost. The primary reason for the cost increase was a change in the design basis from that assumed in 1988. The contract between Ershigs and SCS was signed in January 1991.

- Weekly meetings were held at SCS-Birmingham between Civil, Electrical, I\&C, Mechanical, and Process Engineering disciplines to facilitate communications. Weekly conference calls were also held with the Construction Manager and the SCS Project Manager visited the site at least weekly. Monthly Project review meetings have been held at Plant Yates regularly. Weekly Start-Up Team meetings began in August, 1991.

- Initiated and completed flow modeling work with DynaGen to design liquid collectors for wet duct and chimney operation. Full flow modelling at DynaGen's labs was conducted in August. Followup modelling may be required on one or two unanswered questions. A video of the modelling will be taken.

\section{Task 4 - Construction}

Construction site activities were begun in earnest during the final quarter of 1990 and continue through September, 1991. Georgia Power's completion list includes concrete work for all foundations, the control building, sumps, duct support piers, inlet spray section, slurry tank, wash water tank, ball mill and limestone conveyor system. The control room building exterior was completed and it is being used as a temporary fabrication shop for several crafts while motor control equipment is being installed. After the winding and mounting of the JBR shell and limestone slurry tank, Ershigs' temporary work area was cleared away to make room for the construction of the limestone conveyor system which is underway. Ershigs continued work on JBR internals and also reworked the floor of the JBR to remove some objectionable pin-type fasteners. Ershigs will also replace the warped floor of the limestone slurry tank next quarter. Handwork on the FRP details of the JBR such as inlet and outlet flange overlayment, lower deck beams and placement of the JBR dome is complete. The joining and finishing of the JBR inlet spray section was also completed. Numerous major pieces of mechanical equipment have been delivered and mounted such as slurry pumps, vertical sump pumps, flue gas dampers, JBR sparger tubes and the ball mill. Installation of electrical feeder equipment is $98 \%$ complete with the FGD transformer being "dressed out" by Georgia Power in the April-June 1991 quarter. Conduit trays are currently going up inside the power house and the $4060 \mathrm{kV}$ bus duct is in place. Lesser electrical cable pulls are underway. The inlet ductwork (carbon steel) nears completion and placement after significant rework that had to be done on-site to correct vendor fabrication errors. 
All baseline sampling has been completed with the collection of the last set of samples in July, 1991. A written report will be prepared describing results, however, initial analysis indicates good agreement between laboratories and no significant anomalies in measured parameters noted. Review of the project monitoring plan for the operating period is underway by the Georgia Geological Survey.

\section{Task 10 - Project Management and Reporting}

The management information system continues to be used to control budget and schedule and to help fulfill DOE reporting requirements. Monthly and quarterly reports have been submitted. Weekly meeting with lead engineers and construction management and monthly project review meetings were conducted. Visitors to the site have been numerous including DOE management and representatives from ChiyodaJapan.

\section{Task 11 - Phase II Gypsum Stack Design and Byproduct Studies}

Two of the initial steps in obtaining a permit for the gypsum stacking area have been completed - - zoning approval from Coweta County and site acceptability approval from the Georgia Geological Survey. The last step is approval of the Design \& Operating Plan (D \& O Plan) by the Georgia Environmentai Protection Division (EPD). Using design information from Ardaman on the gypsum stacking area, the D \& O Plan has been completed and submitted for review. Preliminary comments from the EPD indicate that no significant difficulties are apparent, however, additional questions will be forthcoming from the EPD.

The University of Georgia has continued its limited, preliminary investigation and screening of plants which might be candidates for gypsum stack revegetation and for crop yield experiments after process startup. Also, four wallboard manufacturers have agreed to participate in laboratory and manufacturing evaluations of Yates FGD gypsum. Test plan arrangements are currently under negotiations. All four wallboard manufacturers have indicated that the Yates material will probably be too high in 'as-is' moisture and chloride content for immediate use. Therefore, SCS and Georgia Power are presently investigating the requirements for gypsum dewatering and washing prior to shipment for possible expansion of the project's scope.

PHASE III - OPERATIONS, TESTING and DISPOSITION

Not yet underway, begins with system operations. 


\section{Section 5 \\ PLANNED ACTIVITIES}

During the October - December 1991 quarter, the following activities are planned:

- Continue interaction with the State of Georgia on remaining permitting activities.

- Continue all construction activities to keep the project on schedule.

- Begin putting together the Operator Training Plan, the Start-Up Plan and review the Operating Test Plan.

- Resume intensive work on the construction of the gypsum stack.

- Continue all environmental, project management, and reporting activities. 


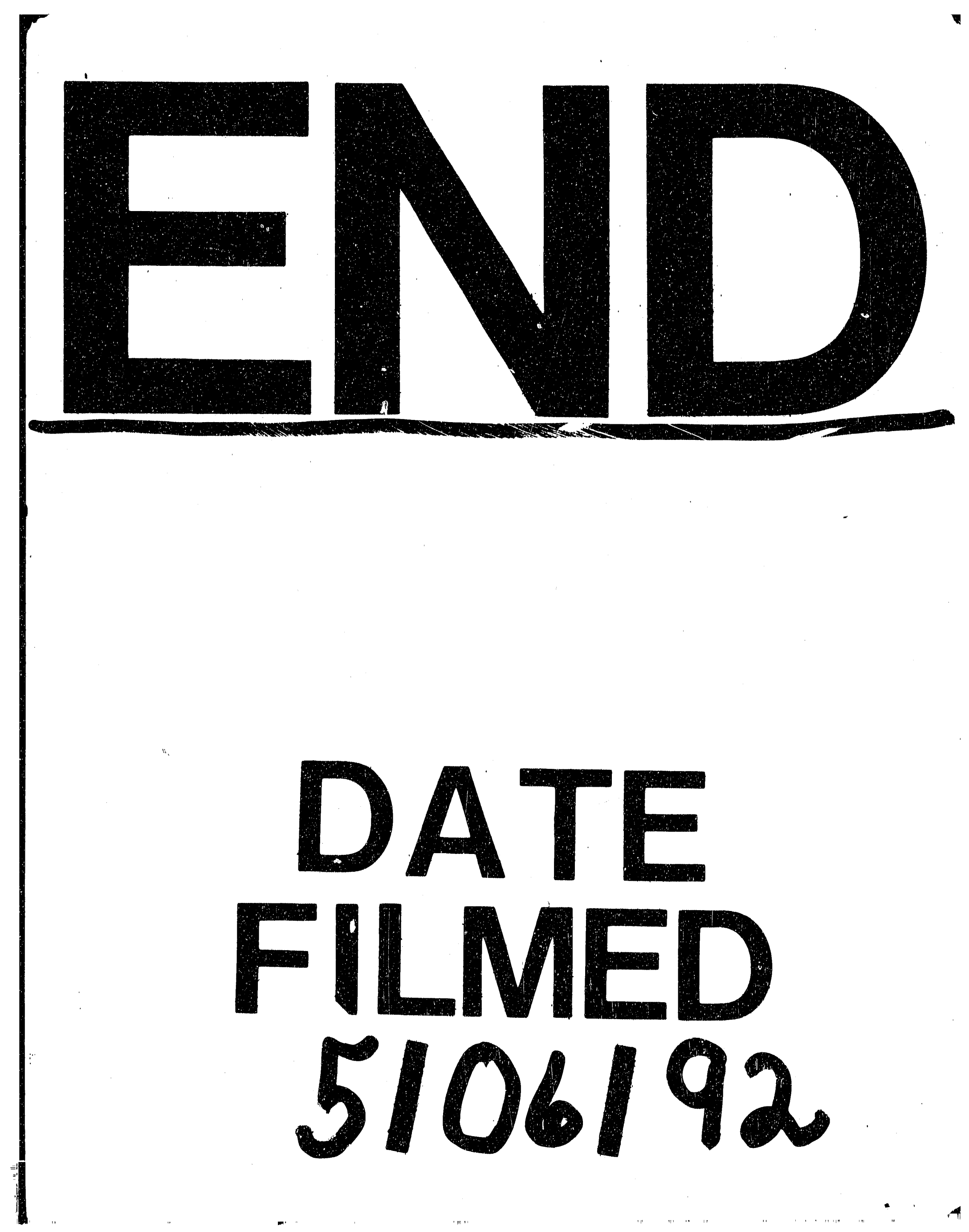




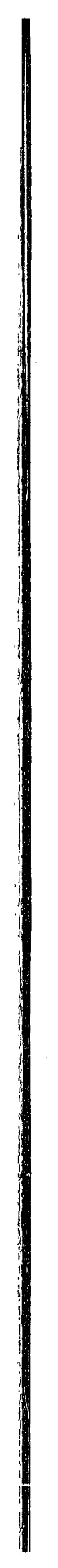

